\section{AEET}

ASOCIACIÓN ESPAÑOLA

DE ECOLOGÍA TERRESTRE

\title{
X Reunión anual de Ecoflor
}

\author{
R. Santos-Gally ${ }^{1, *}$, R. Pérez-Barrales ${ }^{1}$, J. Arroyo $^{1}$, P. Jordano ${ }^{2}$, A. Valido ${ }^{2}$, X. Picó ${ }^{2}$, E. Narbona ${ }^{3}$ \\ (1) Departamento de Biología Vegetal y Ecología, Apdo. de correos 1095, 41080 Sevilla, España. \\ (2) Estación Biológica de Doñana (CSIC), Apdo. de correos 1056, 41013 Sevilla, España. \\ (3) Universidad Pablo de Olavide, Ctra. de Utrera, km. 1, 41013, Sevilla , España.
}

* Autor de correpondencia: J. Arroyo [arroyo@us.es]

> Recibido el 30 de abril de 2013, aceptado el 20 de junio de 2013.

Santos-Gally, R., Pérez-Barrales, R., Arroyo, J., Jordano, P., Valido, A., Picó, X., Narbona, E. (2013). X Reunión anual de Ecoflor. Ecosistemas 22(2):125. Doi.: 10.7818/ECOS.2013.22-2.20

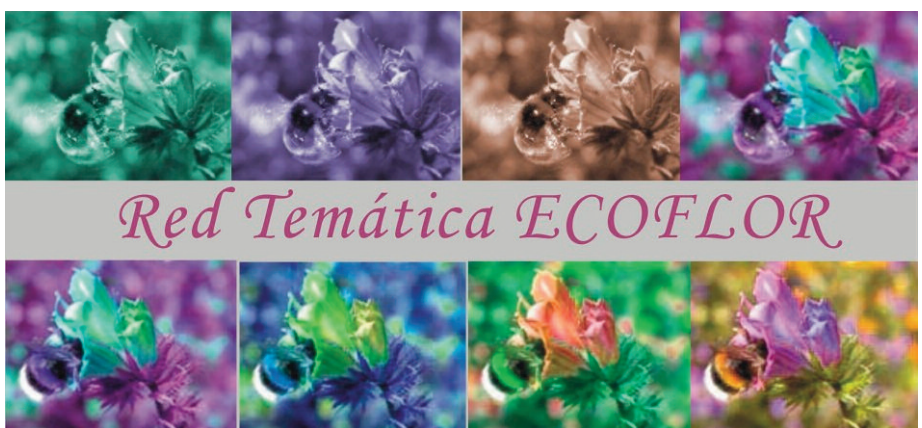

Durante los pasados días 31 de enero y 1 de febrero de 2013 se celebró en Sevilla la X Reunión Anual de ECOFLOR, red temática y grupo de trabajo de la Asociación Española de Ecología Terrestre (AEET), sobre ecología y evolución floral. Esta reunión conmemoró el $10^{\circ}$ aniversario de la creación del grupo, en la misma sede en que se celebró la primera reunión. Fue organizada por los compañeros de tres instituciones sevillanas con amplia representación en ECOFLOR, la Universidad de Sevilla, la Estación Biológica de Doñana (CSIC) y la Universidad Pablo de Olavide. La reunión contó para su preparación con los medios de la Facultad de Biología de la Universidad de Sevilla y el lugar de la reunión fue el salón de actos de la Facultad de Matemáticas de la misma Universidad, que permitió albergar a los 110 asistentes. Los organizadores agradecemos a ambos decanatos su ayuda. Asimismo, se incluyó el conjunto de charlas como parte de una asignatura del Máster Universitario en Biología Evolutiva de la Universidad de Sevilla.
La reunión atrajo la atención de numerosos colegas de toda España e incluso algunos de fuera (Dinamarca, Brasil, Portugal, Alemania), y tuvimos la fortuna de contar con dos conferenciantes plenarios de gran calidad: Scott Armbruster (Universidad de Portsmouth, Reino Unido) y Thomas R. Meagher (Universidad de St. Andrews, Reino Unido), así como 37 charlas más breves de numerosos compañeros que nos mostraron sus trabajos e inquietudes más recientes. Todas las conferencias y charlas se grabaron, y están disponibles para quien quiera verlas y oírlas en: http://tv.us.es/category/videoteca/biologia/

En este repositorio se colocan los vídeos de numerosas actividades, ordenados por orden cronológico de entrada. Para buscar un determinado vídeo de ECOFLOR $X$ es conveniente que lo busquéis primero en el programa, que podéis descargar en: http://webs.uvigo.es/webecoflor/noticias.html\#9

Fueron dos intensos días en los que se pudo comprobar la diversidad temática que abordamos, que trasciende mucho el ámbito estrictamente floral para abordar cuestiones de biología reproductora de plantas más allá de las flores, genética poblacional, análisis comparado, interacciones entre plantas y animales, y diversos niveles de organización, desde el nivel genómico hasta el de redes de interacciones de organismos. Todo ello demuestra que el nivel sigue siendo muy alto y que el futuro, en lo que respecta a la capacidad de los practicantes, está asegurado. Todo esto lo podremos comprobar el año próximo, en la XI Reunión de ECOFLOR, que se celebrará en Puerto Real (Cádiz), gracias a la hospitalidad del compañero Fernando Ojeda, de la Universidad de Cádiz. Nos veremos allí. 